\section{TREATMENT OF DUODENAL ULCER BY A $50 \%$ GASTRIC RESECTION}

BY

\author{
D. C. CORRY, M.D., F.R.C.S. \\ Surgeon, Radcliffe Infirmary, Oxford
}

AND

\section{K. CRONIN, F.R.C.S. \\ Senior Surgical Registrar, Radcliffe Infirmary, Oxford}

For 40 years surgical opinion has wavered between admiration and condemnation of partial gastrectomy as a means of curing duodenal ulcer. Our aim in this paper is to give an account of 128 patients treated by a limited $(50 \%)$ resection Polya gastrectomy during 1950-4. All the operations were done by one of us (D.C.C.) in the belief that the standard three-quarters gastrectomy is both unnecessary and undesirable as a means of lowering the gastric acidity. The objection to any more limited operation has been the high recurrentulcer rate which Armstrong and Penick (1960) reported on as being as high as $10.9 \%$ when only $65 \%$ of the stomach was removed. It is our thesis that if the majority of the short gastric arteries are tied (along with the usual arterial ligations) the acidity is so effectively and permanently reduced that it is unnecessary to do an extensive resection.

Somervell (1943), following the example of Wilson Hey (1937), argued that by ligation of four-fifths of its arteries the acid output of the stomach could be considerably lowered. He performed the operation (" physiological gastrectomy") on 400 patients, and in 1948 could find only one known case of anastomotic ulceration (Somervell, 1948). He admits readily that owing to the conditions under which he worked in India a complete follow-up was impossible. MacLellan (1951) reported a series of 100 patients on whom he had combined arterial ligation with a gastro-enterostomy. Some had been followed for five years and there was only one case of anastomotic ulceration. Quarry Wood (1949) two years before, in a much smaller series of 47 patients treated by "physiological gastrectomy," had three return within two years with recurrent ulcers. For this reason he condemned the operation, and his has been the general view every since. While agreeing that by itself arterial ligation provides no lasting surgical solution to the problem of duodenal ulcer, we believe that when added to a limited resection it gives a future free of the fear of both anastomotic ulcers and a severe dumping syndrome.

Technique of Operation. - The operation as performed since 1943 by one of us (D. C.C.) does not differ in essentials from the standard no-valve ante-colic Polya gastrectomy. There are, however, two points worth making. (1) Approximately half the stomach is removed, the greater curvature being divided a measured 6 in. $(15 \mathrm{~cm}$.) vertically down from the fundus. (2) All the vasa brevia are tied except for the highest one, which is preserved in order to anchor the fundus of the stomach and to help maintain the oesophago-gastric junction.

\section{Clinical Material}

In the five years $1950-4,128$ patients (116 men and 12 women) had a Polya gastrectomy for a chronic duodenal ulcer. This period was chosen for investiga- tion as being recent enough to secure a good follow-up and long enough for post-operative disabilities to appear. Of the 124 patients surviving the operation 116 are available for follow-up. One patient, who is discussed later, died in 1955 after an operation for a gastro-jejuno-colic fistula; seven more are known to have died of causes unrelated to the gastrectomy. One of us (K. C.) has personally interviewed $110(86 \%)$ patients, leaving six whom it has proved impossible to trace. These facts are set out in Table $I$.

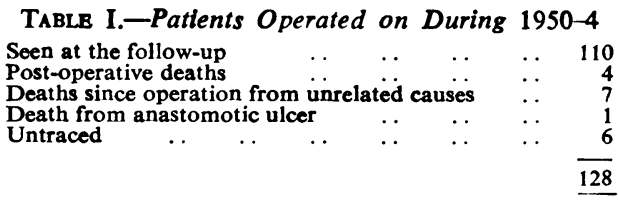

Post-operative Deaths.-There were four postoperative deaths, a mortality of $3 \%$. (1) Man aged 54 died suddenly on the 11 th post-operative day from a rupture of an emphysematous bulla. (2) Man aged 47 died of general peritonitis due to leaking duodenal stump. (3) Man aged 68 collapsed on the second postoperative day and rapidly sank into a state of irreversible shock. Post-mortem examination showed an extensive staphylococcal enterocolitis. (4) Woman aged 56 having made an uncomplicated recovery died suddenly on the 10 th post-operative day from a pulmonary embolus.

\section{Anastomotic Ulceration}

Davey (1959) stated that about $4 \%$ of patients who have had a standard Polya gastrectomy subsequently develop ulcers at the site of the anastomosis. This is almost certainly due to a persistence of the high acidity, and Bruce, Card, Marks, and Sircus (1959) have shown how by using an augmented histamine test meal it is almost possible to forecast the patients who will develop anastomotic ulcers after a standard gastrectomy. The crux of the matter in surgical treatment is therefore to bring down the hyperacidity to a safe level. Visick (1948) solved the problem by doing a seven-eighths gastrectomy, and in the follow-up by Pulvertaft (1952) not a single anastomotic ulcer came to light. Although Pulvertaft did not find any great increase in the number of patients with a dumping syndrome most surgeons are still loath to remove so much of the stomach.

In 1943 one of us (D. C. C.) adopted the operation outlined in this paper. As the Radcliffe Infirmary serves a community with no alternative hospital, surgical failures inevitably return to the original surgeon. A clinical impression that jejunal ulceration is rare in patients so treated has been borne out by the detailed follow-up of the present series. Among this group of 110 patients there has been only one with an anastomotic ulcer-an incidence of $0.8 \%$. The history of this solitary exception is given below.

A man aged 49 had a gastro-enterostomy in 1924 for chronic duodenal ulcer. After this he had repeated episodes of bleeding, and in 1945 a barium-meal examination showed a gastro-jejunal ulcer. In 1953 a partial gastrectomy was done at another hospital, but within nine months he developed another anastomotic ulcer. In 1954 a second gastrectomy was carried out with a Roux-en-Y anastomosis. He returned four months later with a gastro-jejuno-colic fistula, and was referred to the Radcliffe Infirmary. After a preliminary colostomy the fistula was repaired (D. C. C.), the untied vasa brevia were divided, the stomach being transected at a still higher level, and a vagotomy added. He remained well for a year, but in December, 1955, he was 
readmitted with a second gastro-jejuno-colic fistula. This was unravelled for a second time in January, 1956, but he developed a post-operative intestinal obstruction and died.

\section{Dumping Syndrome}

The term "dumping" was first coined by Mix (1922) for the radiological appearances of barium in the small bowel after gastro-enterostomy. The phrase being a vivid one, it has passed into the lingua franca of clinical medicine and is now used as a description of the mass of ill-understood symptoms which may follow partial gastrectomy. There is some difference of opinion on what precisely should be included in the syndrome, but it is now usual (Zollinger and Hoerr, 1947) to divide it into early and late phases. During the former the patient may have a sense of epigastric fullness immediately after meals, occasionaly amounting to an actual discomfort. Sometimes this is accompanied by a feeling of lassitude and muscle weakness, more rarely by vasomotor disturbances such as palpitations, sweating, and hot flushes which are relieved by lying down. The late phase appearing two hours after food is hypoglycaemic in both origin and symptoms and is fortunately rare. Bilious vomiting is something quite separate from "dumping," and is considered later. The numbers and percentages of patients with post-operative disabilities are set out in Table II.

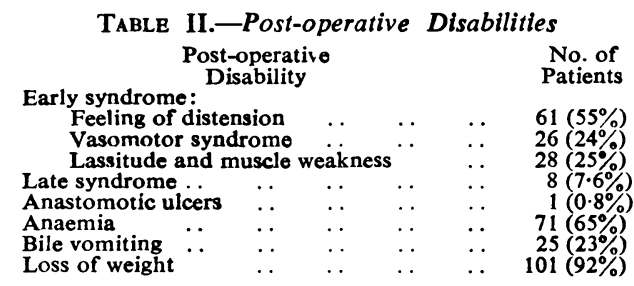

The cause of post-gastrectomy symptoms is of course a perennial bone of contention. All the possibilities from the merely mechanical to the purely biochemical have been canvassed but none are satisfactory. Capper and Welbourn (1955) and Illingworth (1960) have written excellent and balanced reviews of all these different and often mutually contradictory explanations.

Almost rivalling the number of theories on why symptoms occur are the differences of opinion over how often they happen. Hallwright (1957) has collected a table of writers among whom almost any figure can be picked for the incidence of post-gastrectomy symptoms. Part of the reason for this is undoubtedly the grateful patient minimizing his post-operative discomforts. Amidst the confusion surrounding the dumping syndrome there does seem to be general agreement (Wells and MacPhee, 1954) that the more stomach removed the more likely are symptoms and the worse they tend to be. It was in the hope of reducing this disability that in the patients under review only half the stomach was removed. When closely questioned 61 $(55 \%)$ of the patients admitted that they had some epigastric discomfort after eating a large meal, but insisted that they could manage an average one without trouble. This figure is lower than Duthie's (1960), 79\% in a series from Glasgow, where a standard two-thirds to three-quarters gastrectomy had been done. In the same group Duthie found that $47 \%$ had had vasomotor symptoms, whereas without more limited resection this happened only in $24 \%$. Tiredness and muscle weakness occurred in $25 \%$ of our patients.
Many writers (Custer, Butt, and Waugh, 1946; Zollinger and Hoerr, 1947 ; Hobsley and Le Quesne, 1960) have suggested that carbohydrates are particularly at fault in causing the early phase of the post-gastrectomy syndrome. All our patients were asked which foods, if any, they avoided. Sweets, fats, fruits, tea and coffee, hot and cold drinks were each condemned in turn at some time by some patients. It was the quantity not the type of food or fluid which seemed to cause the trouble, and most patients had acquired a nice sense of when they had eaten and drunk enough.

Polya gastrectomy has of course no monopoly in the dumping syndrome, since part or all of it appears whenever and however the stomach is joined to the proximal jejunum. As long ago as 1913 Hurst described all the symptoms we now blame on gastrectomy in patients with gastro-enterostomies. Conceding this, the opponents of the operation believe that removal of the stomach magnifies the slight symptoms of a by-pass into a major handicap. Yet the only penalty our patients suffered (and nearly half escaped this) was the inability to eat a large meal. It therefore seems true that a limited resection avoids all the worst features of "dumping."

\section{Bile Vomiting}

Capper and Welbourn (1955), drawing on the results of nine different surgeons, concluded that bile vomiting occurred in $23 \%$ of patients although it was severe in only $9.6 \%$. Among the patients of the present series $24 \%$ were affected, but it was severe in only one woman. The remainder said that they vomited only once every few months, and none brought up more than a cupful. The single exception was a woman, aged 55, who after a gastrectomy in 1954 was incapacitated by the frequency and amount of her bilious vomiting. A Roux-en-Y conversion (with vagotomy) has greatly relieved her symptoms, but even now she vomits nearly a pint (570 ml.) of bile each day after her main meal.

The vomiting of bile may accompany the early phase of the dumping syndrome but is usually quite separate from it. The exact cause of this troublesome complication is not known. The usual explanation is an obstruction of the afferent loop, but this cannot always be demonstrated at operation. Wells and Johnston (1956) suggest that incompetence of the cardia, preceding or following the gastrectomy, is the main factor.

The most satisfactory method of treatment (Conyers, Hall, Laing, Pulvertaft, and Willson-Pepper, 1960) is to do a Roux conversion. In this the afferent loop is divided off from the stomach and joined lower down to the efferent loop. By this rearrangement the bile avoids the stomach and enters the upper jejunum directly.

\section{Anaemia}

Over 30 years ago Gordon-Taylor, Hudson, Dodds, Warner, and Whitby (1928) reported a $44 \%$ incidence of iron-deficiency anaemia in patients after partial gastrectomy. Since then there have been numerous investigations that have confirmed this finding. Wells and Welbourn (1951) give figures of $15 \%$ for men and $30 \%$ for women, and Blake and Rechnitzer (1953) believe that the highest incidence is in women under the age of 50 . These figures vary, partly because there is no agreement about what is a normal haemoglobin level but also because the length of the follow-up differs from series to series. Lyngar (1950) found that only $2.3 \%$ of 
patients were anaemic at the end of the first year, but this had risen to $30 \%$ after five years. In the present series a normal level of haemoglobin for men has been taken as 90 to $110 \%$ (13.3 to $16.3 \mathrm{~g} . / 100 \mathrm{ml}$.) and 80 to $100 \%$ ( 11.8 to $14.8 \mathrm{~g} . / 100 \mathrm{ml}$.) for women. On the basis of these figures $65 \%$ of the men were anaemic. There were only 12 women in the series, so the figure of $25 \%$ has probably little statistical significance.

That some patients after partial gastrectomy slowly develop an iron-deficiency anaemia is indisputable. What is far from clear is why this should be so. Theoretically the anaemia can arise from an inadequate diet, malabsorption of iron, or increased loss of blood. Hartfall (1934) believed that a faulty diet was the cause. However, not all his patients had been treated by partial gastrectomy, many having had a gastro-enterostomy with little relief of their symptoms. This unhappy group were forced to keep to a restricted diet, and it is perhaps not surprising that they developed an anaemia. Lyngar (1950) in his careful follow-up of patients treated solely by partial gastrectomy could find no evidence that a poor diet was responsible for the anaemia. There is, however, some evidence (Baird, Blackburn, and Wilson. 1959) that the iron intake after gastrectomy is less than normal. The deficiency is not enough to cause anaemia in the male, but may do so in women during the childbearing period of life.

A failure of iron absorption is another suggested cause of the anaemia. As it is well known that acid is necessary to turn the insoluble ferric iron into the soluble ferrous form, it can be argued that a satisfactory post-operative achlorhydria thwarts this essential conversion. Plausible as this may be at first sight, it ignores the fact that many people with achlorhydria show no signs of an iron-deficiency anaemia (Bloomfield and Polland, 1933). Malabsorption may, however, occur after the operation because of food being excluded from the duodenum and passing too quickly through the upper jejunum, the two normal sites of iron absorption. The mechanics of the operation dictate the former handicap, while there is radiological evidence (Glazebrook and Welbourn, 1952) to support the latter. It is these inherent anatomical defects which are probably responsible for any malabsorption rather than the desirable and intentional achlorhydria achieved by partial gastrectomy.

Witts (1956) emphasizes the complexity of the problem and points out that few of the theories put forward have factual support. For his part he suggests that an increased loss of blood may be the basis of the anaemia. In women this can occur from the menses, while in men it can be occult from oesophagitis, gastric erosions, or enteritis rather than occur from a frank stomal ulcer. Bleeding before rather than after gastrectomy may be another origin of the anaemia (Baird et al., 1959), since it can severely deplete the iron reserves of the body. A lowered haemoglobin level can be temporarily boosted with blood transfusion, but unless iron is given after the operation the original deficit is never made good and an insidious anaemia appears.

No one reason explains the iron-deficiency anaemia of partial gastrectomy. It is probably due to many causes, inadequate alone, but which acting in concert are more than enough to produce a severe anaemia in many patients. Fortunately this indecision about aetiology is not reflected in the treatment of the anaemia. Most patients improve rapidly on oral iron, and the minority who fail to do so will respond if the iron is given parenterally.

\section{Loss of Weight}

Many patients tend to lose weight after a gastrectomy. Zollinger and Ellison (1954) believe that if the patient's weight is normal before operation it will be maintained afterwards, and point out that an extensive resection in the underweight patient will lead to still further loss of weight. Brookes, Waterhouse, and Thorn (1960) found that nearly all patients with a peptic ulcer were below weight at the time of operation, and they found a correlation between a post-operative rise in weight and a good result from the operation. Conversely, a further loss of weight usually meant a bad result. Nearly all $(92 \%)$ of our patients lost weight, the average being about $20 \mathrm{lb}$. (9 kg.), but, unlike Brookes et al. (1960), we found no connexion between the amount lost and a good or bad result; some of the patients who were most underweight were the most satisfied of all.

The cause of the loss of weight is not fully understood. Illingworth (1960) thinks that steatorrhoea from intestinal hurry is the most likely explanation. Wollaeger, Comfort, Weir, and Osterberg (1946) studied the fat-excretion in patients after Polya gastrectomy, and, although they found it increased in nearly all, it was excessive in only a few. Johnston, Welbourn, and Acheson (1958) reject malabsorption as a factor and claim that the loss of weight in most cases can be readily accounted for by an inadequate diet. They did, however, admit that the loss of weight in some patients is at present inexplicable.

Apart from allaying the patient's fears, the loss does not need any specific treatment. This is fortunate, because once weight is lost it is difficult to regain in patients after gastrectomy.

\section{Discussion}

Any operation for a duodenal ulcer must leave the patient safe from the threat of anastomotic ulceration while at the same time restoring his digestion to as near normal as possible. Unfortunately, in gastrectomy these twin goals are partly mutually contradictory, because in order to reduce the hyperacidity so much stomach has to be removed that the patient may be left with all the symptoms of dumping.

The variation of the standard Polya gastrectomy described in this paper is partly inspired by Somervell's work (1943) on ligation of the gastric arteries. We feel that the principle of lowering the gastric acidity by reducing the vascularity of the stomach, while sound in theory, is by itself in practice ("physiological gastrectomy") an inadequate answer to the problem of duodenal ulceration. However, we believe that if this same principle is applied by ligating nearly all of the vasa brevia and then adding a limited gastrectomy the acidity drops to safe levels. Moreover, removal of only half the stomach ensures relative freedom from the more disabling aspects of the dumping syndrome. Visick (1948) estimated the results of gastrectomy by allotting his patients to one of four grades: Grade I, no symptoms; Grade II, symptoms which are easily controlled with care; Grade III, symptoms which are not controlled with care; Grade IV, severe symptoms, not improved by the operation.

The same classification has been used in this series (Table III). It can be seen that over $75 \%$ of patients 
fall into grades I and II, and $20 \%$ into grade III. Only one patient of the 110 interviewed said that he was worse after the operation, and the sole patient with an

\begin{tabular}{|c|c|c|c|c|}
\hline \multicolumn{5}{|c|}{ TABLE III } \\
\hline $\begin{array}{ll}\text { Visick grading } \\
\text { No. of patients }\end{array}$ & $35(31 \cdot 8 \%)$ & $51(46 \cdot 5 \%)$ & $22(19.9 \%)$ & $\underset{2(1.8 \%)}{\text { IV }}$ \\
\hline
\end{tabular}

anastomotic ulcer has also been placed in Grade IV. Even the $20 \%$ with a relatively unsatisfactory result were all of the opinion that they were far better than in the days of their ulcer.

\section{Summary}

A review is given of 128 patients with duodenal ulcers treated during $1950-4$ by a limited Polya gastrectomy ; $110(86 \%)$ patients were interviewed.

Only half the stomach was removed.

The importance of ligating the vasa brevia to reduce the gastric acidity is emphasized.

Only one patient $(0.8 \%)$ developed an anastomotic ulcer.

The incidence of the dumping syndrome was much lower than with the standard three-quarters gastrectomy.

Bile vomiting occurred in $23 \%$ of the series, but was severe in only one woman.

Iron-deficiency anaemia was present in $65 \%$ of the men.

Loss of weight occurred in $92 \%$ of the patients. There was no correlation between the result of the operation and the amount of weight lost.

We are grateful to Miss Turner, M.A., the senior almoner, without whose help and ingenuity it would have been impossible to trace many of the patients. We are also indebted to the general practitioners of Oxford who also went to great trouble in helping us to find the patients.

\section{REPERENCES}

Armstrong, R. A., and Penick, R. M. (1960). Ann. Surg., 152 109.

Baird. I. M., Blackburn, E. K., and Wilson, G. M. (1959). Quart. J. Med.. 28, 21 .

Blake, J., and Rechnitzer, P. A. (1953). Ibid., 22, 419.

Bloomfield. A. L., and Polland, W. S. (1933). Gastric Anacidity, p. 95. Macmillan, New York.

Brookes, V. S., Waterhouse, J. A. H., and Thorn, P. A. (1960), Gut, 1, 149

Bruce. J.. Card, W. I., Marks, I. N., and Sircus, W. (1959). Ann. roy. Coll. Surg. Edinb., 4, 85.

Capper, W. M., and Welbourn, R. B. (1955). Brit. J. Surg., 43 24.

Conyers, J. H., Hall, R. A., Laing, D., Pulvertaft, C. N., and Willson-Pepper, J. K. (1960). Brit. Jै. Surg.. 47, 533.

Custer, M. D.. Butt, M. R., and Waugh, J. M. (1946). Ann. Surg.. 123. 410.

Davey, W. W. (1959). Ann. roy. Coll. Surg. Engl., 24, 277.

Duthie, H. L. (1960). Scot. med. J., 5, 127.

Glazebrook, A. J., and Welbourn, R. B. (1952). Brit. J. Surg., 40. 111 .

Gordon-Taylor, G., Hudson, R. V., Dodds, E. C., Warner, J. L., and Whitby, L. (1928). Ibid., 16, 641.

Hallwright, W. W (1957). In The Management of Abdominal Operations, 2nd ed., edited by R. Maingot, p. 738. Lewis, London.

Hartfall, S. J. (1934). Guy's Hosp. Rep.. 84, 448.

Hey, W. H. (1937). Proc. interst. Postgrad. med. Assembl., p. 291.

Hobsley, M., and Le Quesne, L. P. (1960). Brit. med. J., 1, 147

Hurst, A. F (1913). Ann. Surg.. 58, 466.

Illingworth, C. F. W (1960). Gut, 1, 183.

Johnston. I. D. A., Welbourn, R., and Acheson, K. (1958). Lancet. 1. 1242

Lyngar, E. (1950). Acta med. scand., Suppl. 247.

MacLellan, E. (1951). Lancet, 1, 257.
Mix, C. L. (1922). Surg. Clin. N. Amer., 2, 617.

Pulvertaft, C. N. (1952). Lancet, 1, 225.

Somervell, T. H. (1943). Brit. J. Surg., 30, 113.

- (1948). The Surgery of the Stomach and Duodenum p. 271. Arnold, London.

Visick, A. H. (1948). Lancet, 1, 505.

Wells, C., and Johnston, J. H (1956). Ibid., 2, 479.

- and MacPhee, I. W. (1954). Brit. med. J., 2, 1128.

- and Welbourn, R. (1951). Ibid., 1, 546.

Witts, L. J. (1956). Anaemia and the Alimentary Tract, Sydney Watson Smith Memorial Lecture, 1955, Royal College of Physicians, Publication No. 7. Edinburgh.

Wollaeger. E. E., Comfort, M. W., and Weir, J. F., and Osterberg, A. E. (1946). Gastroenterology, 6, 83.

Wood, W. Q. (1949). Arch. Surg., 58, 455.

Zollinger, R. M., and Ellison, E. H. (1954). J. Amer. med. Ass. 154, 811.

— and Hoerr, S. O. (1947). Ibid., 134, 575.

\section{STEATORRHOEA IN PROGRESSIVE SYSTEMIC SCLEROSIS (SCLERODERMA)}

\author{
BY
}

D. J. McBRIEN, M.B., M.R.C.P.

Senior Medical Registrar, St. Thomas's Hospital, London AND

\section{H. E. LOCKHART MUMMERY, M.D., M.Chir. F.R.C.S.}

Consultant Surgeon, St. Thomas's Hospital, London

The purpose of this paper is to draw attention to the fact that progressive systemic sclerosis may present as the malabsorption syndrome or as subacute smallintestinal obstruction in the absence of obvious skin manifestations of the disease.

The continued use of the term "scleroderma" is misleading in that it tends to focus attention on the external manifestations, which, if absent, may prevent the correct diagnosis being considered. For this reason we suggest the use of the term "progressive systemic sclerosis," as originally put forward by Goetz (1954).

\section{Case Report}

A married woman of 43 was first seen in 1954 for an episode of epigastric pain and vomiting. A barium-meal examination showed oesophageal reflux without a hernia and a possible duodenal ulcer. Cholecystogram was normal. In February, 1960, she was seen by a neurologist on account of difficulty in walking for three months. A tentative diagnosis of disseminated sclerosis was made and she was treated with vitamin $B_{12}$ and prednisone. In September, 1960, she was admitted to the Royal South Hants Hospital under the care of Dr. K. Robertson, complaining of nausea, vomiting, diarrhoea, and loss of weight. She mentioned that there was a sensation of food sticking at the level of the lower end of the sternum. On questioning she admitted to Raynaud's phenomenon for about a year, the attacks occurring spontaneously, not particularly on exposure to cold.

Dr. Robertson thought the appearance of the fingers was suggestive of progressive systemic sclerosis.

Investigation revealed a gross steatorrhoea but no anaemia. The glucose-tolerance curve was flat. Xilose tolerance was normal. Plasma proteins showed a low albumin of $2 \mathrm{~g} .1$ $100 \mathrm{ml}$. Electrolytes were normal. Barium-meal examination showed gross dilatation of the small intestine. Biopsy of skin of hand was normal. A diagnosis of stcatorrhoea possibly secondary to scleroderma was made. The patient 